\title{
REFLECTIONS
}

\section{What Are You? A Biracial Physician on Nuanced Racism}

\section{Emma Lo, MD}

Yale University Department of Psychiatry, Connecticut Mental Health Center, New Haven, Connecticut
Conflicts of interest: author reports none.

\section{CORRESPONDING AUTHOR}

Emma Lo, MD

Yale University Department of Psychiatry

Connecticut Mental Health Center

34 Park St.

New Haven, CT 06519

Emma.Lo@yale.edu

\begin{abstract}
A patient shouts what he suspects is my racial background at my face. A colleague repeats a patient's racist remarks against me; I lurk in my whiteness to cope. A compliment about my Asianness lands as a racist devaluation of both sides of my heritage. The medical licensing board does not include my race on its registration form. Straddling the boundary of Asian and White as a biracial female psychiatrist, I struggle to handle exoticization, discriminatory assumptions, and subtle marginalization by patients and colleagues. I grapple with the privilege of light-skinned ethnic ambiguity vs the disrespect for having features deviating from the imagined physician appearance. In this piece, I introduce a nuanced dialog about race and advocate for recognition and inclusion of biracial and multiracial minority medical practitioners who defy oversimplified racial categories.
\end{abstract}

Ann Fam Med 2021;19:72-74. https://doi.org/10.1370/afm.2637.

// V hat are you?" my patient asks.

"Excuse me?" The question is at best rude, and at worst, dehumanizing. I feel like some rare dog breed.

"You know, what's your ethnicity?" His curiosity gives him the right to know about my exotic face. He is not the first.

"Ni-hao! You're Chinese!!!"

"Hi Japan!"

"You're from Singapore!"

"Are you... [Australian, Mexican, Mongolian, Filipino, Korean]?"

I struggle to provide the answer that they don't deserve: "I'm CzechChinese." "I'm half Chinese." Or cheekily, "I'm American."

"You don't look American!"

I am biracial. My father was born in China and raised in Taiwan, later immigrating to the United States with a few dollars and a suitcase to study chemistry. My mother is a "Heinz 57 varieties" mixture of Czech and other European ancestry, who was raised in Wisconsin. In a truly American romance, they met folk dancing in New York City. Growing up, strangers assumed I was adopted.

I am faced with racialized questions and assumptions on a daily basis in my role as a female psychiatrist working with underserved populations with serious mental illness, who are often experiencing homelessness, poverty, and discrimination themselves. Patients' racist statements are tolerated because they are given the convenient excuses of psychosis, intoxication, or poor judgment. Even I forgive my patients for their intrusive inquiries into my identity, simply assuaging their questions so as to move on quickly from the inappropriate subject. At times, I see their invasions sympathetically as earnest, though problematic, means of connecting with another minority. Still, I worry that I only perpetuate bias by enduring their questions politely, or avoiding these uncomfortable scenarios altogether.

My psychotherapy training tells me to ask something like: "What does it mean to you that I look different from other doctors [or colleagues] you 
have had?" This may yield a discussion about their own racialized experiences, or serve as a means to correct expectations about what doctors should look like-if I can tolerate the exchange myself.

To add to the vulnerability I feel, the perpetrators tend to be male. Their aggressive remarks embody a sexism built into our society-and medical culturewhere males can make overly personal observations or inquiries about female medical practitioners, unabashedly. My dual identities, "female" and "biracial," intersect in a struggle to uphold uniqueness and strength against disrespect and exoticization.

Concerned about verifying my heritage, patients ask, "Why don't you speak Chinese?"

And I am reminded of how my father tried to speak to us only in Mandarin, but because my mother was not fluent, our household resorted to our common language: English. I ruminate over the guilty phone calls we had with our Chinese grandparents where I understood few words, and the conversation was predictable:

"How are you?" "Good!"

"Did you eat?" "Yes, very much!"

"You're so cute!" "Thank you."

Colleagues can also inflict pain-sometimes more. "The patient says he 'doesn't trust Orientals," a team member reports. I attribute the patient's remark to paranoia while I hide feeling hurt that my colleague did not come to my defense. His silence perpetuated the patient's racist views; but avoiding moral injury, I convince myself that I was not the patient's target-I'm half-White, to be sure.

During training on how to escape a choke hold by a patient, a peer comments: "You must be really good at this. Martial arts, right?" I wish for the courage to ask him why I would be good at this, but the moment passes and I fall silent-disarmed and distracted for the rest of the day.

"You're Asian. That's why you're so smart," a staff member says to me in the break room. I hesitate, thinking, "Is that a compliment?" I want to say, "I work hard and it has nothing to do with being Asian!" even though I credit my dad with passing down his perfectionism and hard work ethic. Instead I laugh it off and mutter, "Well I'm not that smart, I'm only half-Asian," hating my own inability to confront the microaggression for fear of the awkwardness that could result, and ashamed of my own propagation of this racist viewpoint. I reflect on my upbringing in a White-majority, upper-middle class town, and cringe realizing that my ability to assimilate with Whiteness throughout my life probably privileged me more than my Asianness. I then contend, conflicted, with my colleague's erasure of that half-White ancestry.
When I attempt to renew my medical license, my fractured identity groans at the familiar question.

Race: (select one)

O American Indian or Alaska Native

O Asian

O Black or African American

O Native Hawaiian or other Pacific Islander

O White

There is no "Other" category, and the system does not allow me to choose more than one race. The attendant suggests that I "just pick one."

I click back and forth between "White" and "Asian." Am I supposed to choose between my mom and my dad? Do I feel more White or more Asian? I have never felt like I could blend in with White people-obviously looking different from them-or Asian people-not speaking an Asian language or connecting over a common home culture. I spent my childhood wishing-and pretending-away my Asianness for the sake of fitting in at a predominantly White school. Yet I have clicked "Asian" before, internalizing the false assumption that if people can identify with a minority race, they should. Indeed, I have had the privilege of being a racial chameleon, hiding in the cover of ethnic ambiguity or Whiteness when advantageous to me, and holding close people of color when feeling victimized. I actually feel most connected to people who are biracial, who are navigating the boundary of two worlds, who struggle to place themselves in categories that are artificially generated, who serve as entertaining guessing games for those who are too ignorant to appreciate the dynamic identities of our modern mixing pot. I simultaneously embrace and resent checking "Other" when available; while it empowers me to deny the stated boundaries placed upon me, it is itself an othering experience. As biracial humans we obscure the spirit of race itself, and are ourselves confused where we should fit in, in a world that revolves around categories, and delights in othering. These checkboxes fail to capture my fluid and multidimensional experience.

As medicine grapples with promoting diversity and inclusivity in an ever-evolving racial landscape, it is imperative that we understand and validate the experiences of all minority medical practitioners. Racial discrimination against trainees and medical practitioners in clinical settings is well documented, along with its negative consequences. ${ }^{1-4}$ However, rarely do these investigations explore the boundaries between racial groups to understand the complex experiences of biracial and multiracial individuals. Clinical research often relies upon US Census Bureau categories, ${ }^{5}$ which only began allowing participants to "mark one or more" races in the year $2000 .{ }^{6}$ Racial categories have 
evolved as they are criticized for biased flaws, oversimplification of race, biologic inaccuracy, and outright irrelevance. ${ }^{5}$ Still, asking about race can track racial inequity to promote social justice. Research should better characterize the varied experiences of biracial and multiracial individuals. It should question the purpose of racial checkboxes, identify groups who may be excluded, and ensure that data are used to promote racial equity. Training can arm clinicians to confront their own implicit biases and respond to microaggressions, ${ }^{7-9}$ but should specifically address the complexities of biracial and multiracial experiences. Guided forums that explicitly invite dialogs about race can improve attitudes about race and foster a safer work environment for people of all racial backgrounds, ${ }^{10-11}$ but they should feel inclusive to those defying categorical racial subtypes. Until the medical community appreciates a nuanced view of race, biracial and multiracial people should not be forced to choose a checkbox or a side; nor are we a sum of our parts.

Even in conversations about race in the workplace, I wonder where I fall. Does my half-Whiteness land me safely within the majority? Is my half-Asianness enough to allow me to identify as a persecuted minority? As I search for my place in the fight for collective liberation of all minoritized peoples, I know that I am uniquely positioned-my relative White proximity comes with a duty to speak out in circles of power; meanwhile, I proudly rise in solidarity with Black, Indigenous, and other people of color.

Occasionally my ethnic ambiguity works in my favor: "You look like you're Puerto Rican. You're my sister."

I just gaze at my notoriously grumpy patient, and smile.

To read or post commentaries in response to this article, see it online at https://www.AnnFamMed.org/content/19/1/72.
Submitted May 29, 2020; submitted, revised, October 13, 2020; accepted October 22, 2020.

Key words: biracial; multiracial; race; racism; minorities; discrimination; physician

Funding support: This work was funded in part by the State of Connecticut, Department of Mental Health and Addiction Services, but this publication does not express the views of the Department of Mental Health and Addiction Services or the State of Connecticut. The views and opinions expressed are those of the author.

\section{References}

1. Fnais $\mathrm{N}$, Soobiah $\mathrm{C}$, Chen $\mathrm{MH}$, et al. Harassment and discrimination in medical training: a systematic review and meta-analysis. Acad Med. 2014;89(5):817-827.

2. Nunez-Smith M, Pilgrim N, Wynia M, et al. Health care workplace discrimination and physician turnover. J Natl Med Assoc. 2009; 101(12):1274-1282.

3. Osseo-Asare A, Balasuriya L, Huot SJ, et al. Minority resident physicians' views on the role of race/ethnicity in their training experiences in the workplace. JAMA Netw Open. 2018;1(5):e182723.

4. Filut A, Alvarez M, Carnes M. Discrimination toward physicians of color: a systematic review. J Natl Med Assoc. 2020;112(2):117-140.

5. Callier SL. The use of racial categories in precision medicine research. Ethn Dis. 2019:29(Suppl 3):651-658.

6. Strmic-Pawl HV, Jackson BA, Garner S. Race counts: racial and ethnic data on the U.S. Census and the implications for tracking inequality. Sociol Race Ethn. 2018;4(1):1-13.

7. Williams JC, Rohrbaugh RM. Confronting racial violence: resident, unit, and institutional responses. Acad Med. 2019;94(8):1084-1088.

8. Sherman MD, Ricco J, Nelson SC, Nezhad SJ, Prasad S. Implicit bias training in a residency program: aiming for enduring effects. Fam Med. 2019;51(8):677-681.

9. Wheeler DJ, Zapata J, Davis D, Chou C. Twelve tips for responding to microaggressions and overt discrimination: When the patient offends the learner. Med Teach. 2019;41(10):1112-1117.

10. Nunez-Smith M, Curry LA, Berg D, Krumholz HM, Bradley EH. Healthcare workplace conversations on race and the perspectives of physicians of African descent. J Gen Intern Med. 2008;23(9): 1471-1476.

11. Bright HR, Nokes K. Impact of a discussion series on race on medical student perceptions of bias in health care. PRiMER. 2019;3:29. 